\title{
O olhar predador: A arte e a violência do olhar
}

The Predatory Gaze: The Art and Violence of the Gaze

Le regard prédateur : l'art et la violence du regard

\section{Angélica Lima Cruz}

\section{(2) OpenEdition}

\section{Journals}

Edição electrónica

URL: http://journals.openedition.org/rccs/3685

DOI: $10.4000 /$ rccs.3685

ISSN: 2182-7435

\section{Editora}

Centro de Estudos Sociais da Universidade de Coimbra

Edição impressa

Data de publição: 1 Junho 2010

Paginação: 71-87

ISSN: 0254-1106

Refêrencia eletrónica

Angélica Lima Cruz, "O olhar predador: A arte e a violência do olhar », Revista Crítica de Ciências Sociais [Online], 89 | 2010, colocado online no dia 01 outubro 2012, criado a 01 maio 2019. URL http://journals.openedition.org/rccs/3685; DOI : 10.4000/rccs.3685 


\section{ANGÉLICA LIMA CRUZ}

\section{O olhar predador: A arte e a violência do olhar'}

Na primeira parte deste ensaio é abordada a forma como a teoria feminista tem reflectido a prática artística, constituindo-se como um contributo para o conhecimento sobre as relações entre artes visuais, sexualidades e poder. Depois de uma breve apresentação do tratamento do nu feminino e do corpo da mulher nos diversos movimentos artísticos ao longo da história da arte ocidental, é abordado o lugar, ou não lugar, que coube às mulheres na arte, nomeadamente na pintura.

Palavras-chave: arte feminista; discriminação contra as mulheres; história da arte; pintura; poder; sexualidade; violência simbólica.

\section{O olhar predador: o uso e abuso do poder do olhar}

No pensamento pós-moderno podemos falar de múltiplos olhares ou formas múltiplas de ver. Esta multiplicidade nem sempre é confortável: seria mais fácil acreditarmos que há só uma verdade a ser descoberta, uma resposta verdadeira para todas as perguntas, logo também uma forma de olhar mais verdadeira do que as outras. Pensando nestas múltiplas formas de ver, propomos uma leitura de imagens no ensino das artes visuais, reflectindo sobre o modo de ver contaminado por questões de diferença sexual e sobre os poderes que dizem respeito a este campo de saber chamado "arte". Olhamos como mulheres, do ponto de vista de um 'outro' que não tem estado lá. As mulheres têm sido um dos "outros", tanto no discurso sobre as artes, como na produção artística.

\section{Feminismo e arte: uma perspectiva histórica e teórica}

A abordagem feminista em história de arte pressupõe a ideia de que a diferença sexual é um elemento essencial no entendimento da criação, conteúdo e avaliação da obra de arte. Nem arte nem artistas, de acordo com o ponto

\footnotetext{
${ }^{1}$ Este artigo teve o apoio do projecto PIHM/VG/0016/2008, financiado pela FCT em protocolo com a CIG: Amor, Medo e Poder: percursos de vida para a não violência/Love, Fear and Power: Pathways to a Non-violent Life.
} 
de vista feminista, podem ser entendidas/os fora do seu contexto. Os desafios feministas têm dois campos: por um lado, reconhecer e documentar a discriminação das mulheres enquanto artistas e sujeitos de arte; por outro lado, narrar a forma como as historiadoras de arte feministas têm sido agentes na recolha de informação acerca da contribuição das mulheres, tanto como artistas, mecenas ou clientes (Adams, 1996: 79).

Um dos contributos importantes das feministas para o debate e reflexão sobre a história da arte é a denúncia da forma como os homens, ao longo da história, têm tido mais acesso à educação artística do que as mulheres, questão a que regressaremos no final deste ensaio. Uma das razões que impedia as mulheres de aceder à carreira artística e nela progredir tem a ver com o facto de, durante muito tempo, ter sido considerado inapropriado, para a mulher, desenhar a partir de modelo nu. ${ }^{2}$ Outro contributo das perspectivas feministas ${ }^{3}$ para a discussão consiste em terem realçado os efeitos iconográficos do pressuposto de que tanto artista como público são masculinos. Várias teóricas feministas argumentam que a mulher representada é objecto do gaze do homem (o sujeito activo do olhar) ${ }^{4}$ (Mulvey, 1975).

Ninguém melhor do que Linda Nochlin, em 1971, questionou as razões por que não existiam grandes artistas mulheres, enquanto simultaneamente apelava a uma crítica feminista da história de arte (Nochlin, 1989).5 No seguimento de Nochlin, também Griselda Pollock (2007) desenvolve a importância de uma crítica feminista da arte "que pudesse superar as limitações ideológico-culturais e revelar os desvios e as insuficiências, não só

\footnotetext{
${ }^{2}$ Whitney Chadwick (1996) abre a sua obra com a referência ao retrato/pintura de Johann Zoffany, de 1772, para comemorar a fundação, em 1768, da British Royal Academy, referindo que às mulheres foi impedido estudarem o modelo nu. Como isto constituía a base da pintura erudita da época, às mulheres, mesmo quando membros, como era o caso de Angelica Kauffmann e Mary Moser, ambas filhas de pintores membros desta academia (o que certamente terá facilitado a sua entrada), não lhes era permitido participar em todas as dimensões da actividade artística da academia (1996: 6 e 7; ver também Perry, 1999: 90). É significativo que o pintor as tenha incluído apenas como retratos na parede, e não ao lado dos seus colegas, na aula de modelo.

${ }^{3}$ Salientamos, aqui, algumas perspectivas feministas, conscientes de que o feminismo não é uma abordagem homogénea, sendo que a sua diversidade tem contribuído quer para a sua riqueza quer para o diálogo que permite avançar no conhecimento.

${ }^{4}$ Laura Mulvey (1975) desenvolveu o conceito de male gaze quando, ao fazer a distinção analítica entre emissão e recepção, analisou o espectador ideal, argumentando que as imagens oferecidas por Hollywood tinham o objectivo de fomentar o prazer visual masculino, que ela "interpreta com os paradigmas da psicanálise, incluindo scopophilia e voyeurismo" (Sturken e Cartwright, 2001: 76). O conceito de gaze tem, fundamentalmente, a ver com a relação entre o prazer e as imagens. Male gaze é aqui desenvolvido no sentido do poder de quem olha e do desapossamento de quem é olhado (idem: 76), salientando-se igualmente a dimensão do olhar colonizador. A este propósito, ver também Berger (1972) e ainda Rose (2005).

5 Nochlin publicou pela primeira vez o ensaio "Why Have There Been No Great Women Artists?" em Art News, 69(9), 22-39, incluindo mais tarde em Women, Art, and Power (1989).
} 
em relação à questão das mulheres artistas, mas também na formulação das perguntas cruciais da disciplina", acrescentando ainda que "nenhuma mudança será profunda a não ser que inclua a questão da diferença sexual" (Pollock, 2007: 90). Assim, o feminismo é, na sua diversidade, o único discurso e a única prática social que aborda e sublinha as questões da diferença sexual, questões estas que muitos outros críticos, mesmo progressistas, preferem esquecer, sob o falso neutro (Barreno, 1985), ou reduzir à categoria de secundárias ou mesmo triviais.

As teóricas citadas desocultaram ainda a conexão entre a subalternização das mulheres e a representação visual dentro da arte e da cultura (Harris, 2001). ${ }^{6}$ Linda Nochlin afirma que as mulheres devem deixar de se ver como parte de um problema observado pelos olhos da "elite dominante masculina que está no poder" (Nochlin, 1989: 151), incitando-as a inventar as suas próprias perspectivas intelectuais nas artes e noutras áreas. Harris (2001) vem reforçar o argumento desta autora relativamente à necessidade de questionar a representação do artista como um criador socialmente isolado, para o recolocar dentro de uma história social da arte, recomendando que o estudo feminista seja enraizado numa análise do contexto social e histórico mais alargado.

Será este entendimento das estruturas sociais públicas, mais do que da actividade dos artistas individuais em particular, que proporcionará respostas convincentes às questões feministas fundamentais. Porque é que as mulheres não tiveram um lugar significativo nas histórias tradicionais de arte e porque é que as mulheres, aparentemente, não conseguiram êxito como artistas desde o Renascimento? (Harris, 2001: 99)

Ainda segundo Nochlin - num argumento que subscrevemos - a história de arte dominante ou tradicional não tem qualquer capacidade para lidar com a questão da relação entre o social e o valor do objecto artístico, porque a história de arte é determinada por preceitos centrais sobre o indivíduo e a criatividade, que não deixam espaço para pensar o social. Nochlin alerta que nós, feministas, não devemos "engolir totalmente a 'isca' de tais mitos e limitarmo-nos simplesmente a 'reabilitar' ou a 'redescobrir' exemplos de mulheres artistas insuficientemente apreciadas" que a história tradicional tenha ignorado; esta versão da história de arte apenas se constituiria

\footnotetext{
${ }^{6}$ Jonathan Harris (2001) faz, no capítulo 3, "Feminism, Art and Art History" (pp. 95-127), uma análise crítica dos seguintes "textos-chave": Linda Nochlin (1971); Rozsiska Parker e Griselda Pollock (1981); Griselda Pollock (1982); Lucy Lippard (1980) e Anne Middleton Wagner (1996).
} 
como somatório e não como re/conhecimento da realização das mulheres e da história da arte em geral (Nochlin, 1989: 147).

As historiadoras de arte feministas, atrás citadas, têm mostrado que as mulheres que conseguiram um êxito moderado como artistas quase sempre provêm das classes sociais no poder e, em muitos casos, os seus pais também foram artistas. ${ }^{7}$ No entanto, apesar destes poucos exemplos, desde o Renascimento até à dissolução efectiva das instituições estatais - como as academias dos finais do século XIX -, as mulheres foram sempre sistematicamente excluídas, ou ocuparam apenas posições marginais, dentro das instituições de educação artística e exposição. No Renascimento, Giorgio Vasari $(1998)^{8}$ até refere três artistas mulheres - Properiza de Rossi, Sofasnisba Anguissola e Plautilla Nelli - mas, no século Xx, as histórias de arte ocidental, em regra, ignoram totalmente as mulheres. Por exemplo, a History of Art de H. W. Janson (in Addiss e Erickson, 1993), na sua primeira edição, de 1962, não refere uma única mulher artista. No entanto, na edição de $1986\left(3^{a}\right)$, refere vinte e uma mulheres artistas, num total de quatrocentos e trinta artistas referenciados (Addiss e Erickson, 1993), o que não deixa de representar uma mudança. ${ }^{9}$ Maria José Magalhães aborda, no seu ensaio "Activismo feminista e desconstrução da violência contra as mulheres”, nesta revista, o papel de alguns movimentos de artistas feministas de intervenção, como as Guerrilla Girls, na denúncia desta desigualdade.

Historiadoras de arte feministas, como Rozisca Parker e Griselda Pollock colocam as seguintes perguntas: "porque foi necessário negar uma parte tão grande da história da arte, repudiar tantas artistas, denegrir tantas obras de arte, simplesmente porque foram criadas por artistas mulheres? O que é que isto revela acerca das estruturas e das ideologias da história de arte, como define o que é e o que não é arte, a quem se atribui o estatuto de artista e o que significa esse estatuto?" (1981: xviii). As autoras questionam ainda o facto de esta omissão ter ocorrido precisamente no século que assistiu a um maior desenvolvimento dos movimentos para a emancipação social e expansão da educação das mulheres - o século xx (Parker e Pollock, 1981; ver também Harris, 2001). No entanto, no século XIX, algumas mulheres artistas, como, por exemplo, Berthe Morisot, Mary Cassat, Susanne Valadon, Paula Modersohn-Backer, embora excluídas da formação académica, de concursos de prestígio e de formas de exposição controladas pelo Estado,

\footnotetext{
${ }^{7}$ Podemos referir Artemisia Gentileschi (século xvII, filha de Orzio Gentileschi), assim como Angelica Kauffmann e Mary Moser (filha de George Moser) (século XvIII).

${ }^{8}$ Pintor e historiador, além de arquitecto, que publica, no século Xvi, $A$ vida dos artistas.

9 Vale a pena acrescentar que, no catálogo do MOMA, Nova Iorque, de 2000, de entre 240 artistas, apenas 13 são mulheres.
} 
negociaram a sua posição e conseguiram fazer arte "tanto por causa como apesar da sua diferença” (Harris, 2001: 105). Daí que a história das mulheres na arte não deva ser apresentada simplesmente como uma luta contra a exclusão e discriminação pelas instituições: deve ainda incluir a história das que conseguiram algum sucesso, apesar de todos os obstáculos. ${ }^{10}$

Vale a pena recordar a exposição "Social Strategies by Women Artists", que Lucy Lippard organizou em Londres em 1980. O objectivo da organizadora era "substituir a ilusão de liberdade estética neutra" (Lippard, 1995: 150) e afirmar uma posição política em arte (Lippard, 1981/2006). Numa variedade de formas rompendo com o sentido de que o "feminismo" significa uma só mensagem política ou um só tipo de obra artística, a autora incluiu na exposição obras que tratam de assuntos como o aborto, os anticoncepcionais, os cuidados domésticos, os perigos do trabalho, o sexo e as profissões. Lippard refere que todas as artistas presentes na exposição tiveram algum êxito dentro do mundo artístico dominante. O dilema que ela colocou na altura continua actual nos dias de hoje. Em seu entender, continua a não haver acordo entre se as mulheres artistas deveriam procurar o êxito dentro desse mundo dominante ou considerar o sucesso comercial irrelevante e pensar em espaços alternativos. Em resposta a este dilema, muitas feministas, como Nochlin, Parker e Pollock, estavam conscientes dos perigos dum feminismo institucional, com alguma presença nos anos 1970 e 1980, e consideraram-no parte do problema ao levar ideias e políticas radicais para dentro das instituições, como as universidades, onde a absorção pelo sistema é sempre possível.

Sobre esta questão, a perspectiva de Anne Middleton Wagner (1995) - também analisada por Jonathan Harris (2001) - é ligeiramente diferente, na medida em que ela, tal como Linda Nochlin, concorda que existe uma grandeza na arte que vai para além do que é ideologicamente perpetuado pela história de arte patriarcal. Nomear o valor de uma obra de arte significa atribuir-lhe significado e relevância cultural. Embora hoje possamos afirmar que não existe apenas um padrão único para a atribuição deste valor, todavia, o inverso também não é verdadeiro, ou seja, não é pelo facto de ser produzido por mulheres que um objecto de arte tem um valor caucionado à partida.

É nos anos 1970, também em consequência do movimento feminista de segunda vaga e desta crítica feminista da arte, que as mulheres artistas se vão consciencializando cada vez mais como sujeitos, tomando em muitas ocasiões o seu corpo como instrumento e suporte da sua obra, ora em

10 Sobre estes obstáculos consultar também Angélica Lima Cruz (2002). 
performances, ora documentando acções em fotografia ou vídeo. Dentro do paradigma dominante da cultura ocidental, não é só a diferença biológica que constitui diferença. A artista feminista lésbica Harmony Hammond (1994/2006) reforça a importância de, em ordem a lutar pela visibilidade das artistas mulheres, se insistir na elaboração, recuperação e reconstrução de uma história que permita um "diálogo generativo" (560), capaz de trazer à memória artistas esquecidas (incluindo lésbicas) e criar espaços para as novas gerações. A teoria queer e os estudos culturais têm trabalhado no sentido da visibilização destas diferenças.

Dentro do feminismo, há muitas abordagens: umas mais empenhadas em identificar os modos como a "feminilidade" é evidenciada na representação, outras em produzir uma prática cultural que resista ao posicionamento da mulher como espectáculo, ou objecto do male gaze, e outras ainda que se concentram em criar ou transformar estruturas hierárquicas de dominação.

\section{A violência do olhar}

O questionamento feminista da história de arte canónica define-a como uma arte contada de uma só perspectiva, uma perspectiva eurocêntrica e falocêntrica: a história de arte do homem branco ocidental. A própria arte fala-nos da visão e das posições a partir das quais vemos e somos vistos. Como já referimos anteriormente, em vez de se terem concentrado na celebração da/o "grande artista", os estudos críticos feministas de arte têm vindo a analisar as suas formas de representação, assim como os modos como a disciplina de história d'arte nos ensina - isto é, nos organiza e disciplina para que vejamos a arte de um ponto de vista limitado. Isto levou a que algumas historiadoras de arte considerassem a narração canónica da arte, e em particular o seu discurso sobre o nu feminino, como uma estrutura que forma um clube exclusivamente masculino e heterossexual.

\section{Modelo nu}

\section{Homens que pintam corpos (nus) femininos}

Uma das formas de analisar o papel das mulheres, na história da arte europeia, é olharmos a construção sociohistórica da pintura do modelo nu. No já referido retrato de grupo de Johann Zoffany, celebrativo da fundação da British Royal Academy, em 1968, Angelica Kauffmann e Mary Moser não foram incluídas entre os artistas dispostos casualmente em volta dos modelos masculinos nus; foram-no apenas através dos seus retratos na parede. Mas a principal segregação das mulheres residiu no facto de serem impedidas do estudo de modelo nu, que foi a base do ensino da representação 
desde o século XVI até ao século XIX. Depois de Kauffmann e Moser, até ao século XX, mais nenhuma mulher foi aceite como membro desta academia (Chadwick, 1996: 7). Kauffmann trabalhava dentro das convenções do discurso académico com temas históricos e mitológicos. O seu trabalho foi, no entanto, criticado pela suavidade das suas figuras, sugerindo-se, na época, que a pintura histórica não era um modo 'natural' de expressão para mulheres pintoras, para as quais géneros menores, como retrato e flores, seriam mais adequados. Moser era identificada pelo seu trabalho com flores, um género menos valorizado. Mais ainda, a exclusão das mulheres dos programas de ensino das academias significou que as suas carreiras não puderam progredir seguindo as mesmas etapas das dos seus colegas masculinos.

Foi o impedimento da prática artística do desenho e pintura de nu que fez com que ficassem reservadas às mulheres as actividades de pintura de menor valor na época: flores, naturezas mortas, pintura de género ${ }^{11} \mathrm{e}$ retrato, o que se tornou, naturalmente, num obstáculo à sua inclusão no mainstream. ${ }^{12}$ As mulheres não podiam entrar pela porta grande do edifício da arte: estavam circunscritas à porta das traseiras. Há que ressalvar, no entanto, uma excepção nesta história da relação entre as mulheres pintoras e o nu: no século XVII, aparece um nu feminino pintado por uma mulher, Artemisia Gentileschi, uma versão do episódio bíblico conhecido como "Susana e os Velhos" [fig. 1]. Até aos finais do século Xx, a autoria do quadro foi atribuída ao seu pai, o pintor Orazio Gentileschi, tendo sido Mary Garrard (1982) quem finalmente estabeleceu Artemisia Gentileschi como autora dessa obra.

$\mathrm{Na}$ história das artes ocidentais - na literatura, na pintura e na escultura o corpo feminino despido figura frequentemente, particularmente na mitologia greco-romana e, em menor número, no Antigo Testamento. "Susana e os Velhos" foi um tema tratado por diversos pintores ao longo dos tempos. ${ }^{13}$ Nele é representado o momento em que os dois velhos vão ao jardim de Joaquim para seduzir a sua esposa Susana. Poucos temas artísticos oferecem a oportunidade de analisar criticamente a legitimação

\footnotetext{
${ }^{11}$ Designa-se pintura de género aquela que aborda a representação de costumes - festas, rituais, cenas domésticas, cenas de caça, etc.

12 Por oposição ao mainstream, Collins e Sandell (1987) trazem o conceito de biddenstream para abordar aquela produção cultural e artística, habitualmente conotada com as mulheres, na sombra, invisível, sem reconhecimento social, que se pode caracterizar pela continuidade sobre a mudança, esforço cooperativo e anónimo (Collins e Sandell, 1987). Também Maria Irene Ramalho Sousa Santos se refere a estes serviços como "tão insignificantemente essenciais que nem merecem menção, por ser impossível imaginar o dia-a-dia sem eles" (Santos, 1980: 119).

${ }_{13}$ De entre as 47 encontradas, seleccionamos as seguintes: Tintoretto (1562); Artemisia Gentileschi (1610); Alessandro Allori (1535-1607); Rembrandt (1647); J-Baptiste Santerre (1709); Gyula Tornai (1851-1908); Thomas Hart Benton (1939).
} 


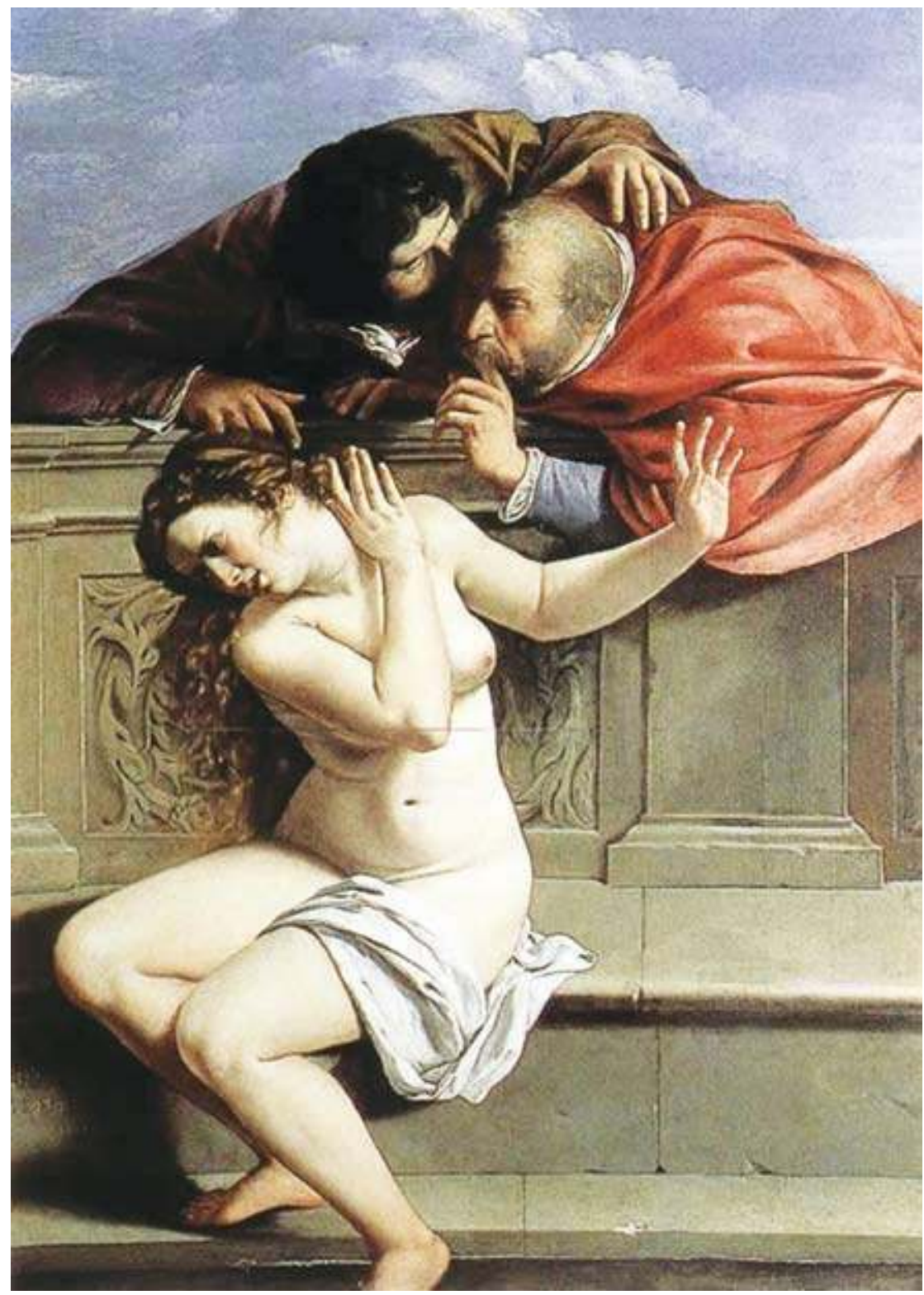

FIGURA 1 - Artemisia Gentileschi, Susana e os Velhos, 1610 
do voyeurismo como "Susana e os Velhos". Além do voyeurismo, podemos encontrar aqui a objectificação da mulher, assim como a perpetuação da violência patriarcal (ver Cruz e Magalhães, 2009). Este tema, segundo Garrard (1982), foi tratado por artistas como oportunidade de exibir o nu feminino, com o apelo erótico do nu, sublinhado pela presença dos dois velhos lúbricos, cuja inclusão foi tanto iconograficamente justificada como pornograficamente eficaz.

Quando a tradição da pintura se laicizou, outros temas ofereceram a oportunidade de pintar nus. Porém, em todos eles está implícito que o modelo tem consciência de estar a ser visto por um espectador. A quase totalidade das obras de arte dos últimos séculos foi encomendada por varões, fossem eles chefes religiosos, reis e aristocratas, ou ricos burgueses. Igualmente, e até ao século XX, as obras de arte foram imaginadas e realizadas por homens, factores que contribuíram para que as Artes Visuais reflectissem, quase em exclusivo, o ponto de vista masculino. De facto, os museus e as galerias de arte do passado estão cheios de nus femininos e quase não se encontra o seu equivalente masculino (Cruz e Magalhães, 2009).

O modernismo na pintura, que significou uma ruptura com padrões culturais dominantes desde o Renascimento, em termos estéticos e formais, não rompeu, no entanto, com a violência do olhar ( gaze) masculino e do olhar colonizador. Poder-se-ia mencionar, entre outros, os trabalhos de Gauguin, Picasso ou Matisse. Les Demoiselles d'Avignon (1901) [fig. 2], considerada uma peça importante do cubismo e uma das mais famosas de Picasso, é exemplar deste olhar predador sobre o corpo feminino sexuado através das imagens canónicas da arte ocidental. Nessa imagem, podemos ver cinco prostitutas num bordel. Os seus corpos estão numa atitude passiva, à espera de serem requisitados. Enquanto, em relação a este e outros quadros, tanto de Picasso como de outros artistas modernistas, foram enaltecidos os seus aspectos formais, a sexualidade feminina fica em silêncio. Há uma naturalização do corpo da mulher como objecto do olhar na arte, ao que acresce a apropriação do artista da chamada "arte primitiva", "arte negra" ou "arte exótica". Aqui, a atitude estética de Picasso traduz-se na supremacia de valores masculinos, brancos e europeus.

Embora o nu feminino na arte ocidental estivesse em evidência de forma mais ou menos constante ao longo da sua história, isto não quer dizer que a mulher (como sujeito) e a sua sexualidade também o estivessem. Na verdade, nas representações dos nus femininos, é da sexualidade masculina que se fala, enquanto a sexualidade feminina é calada e, de alguma forma, disciplinada. Uma grande parte das imagens da arte ocidental subentende um espectador masculino, de forma quase óbvia. Essas imagens são dirigidas 


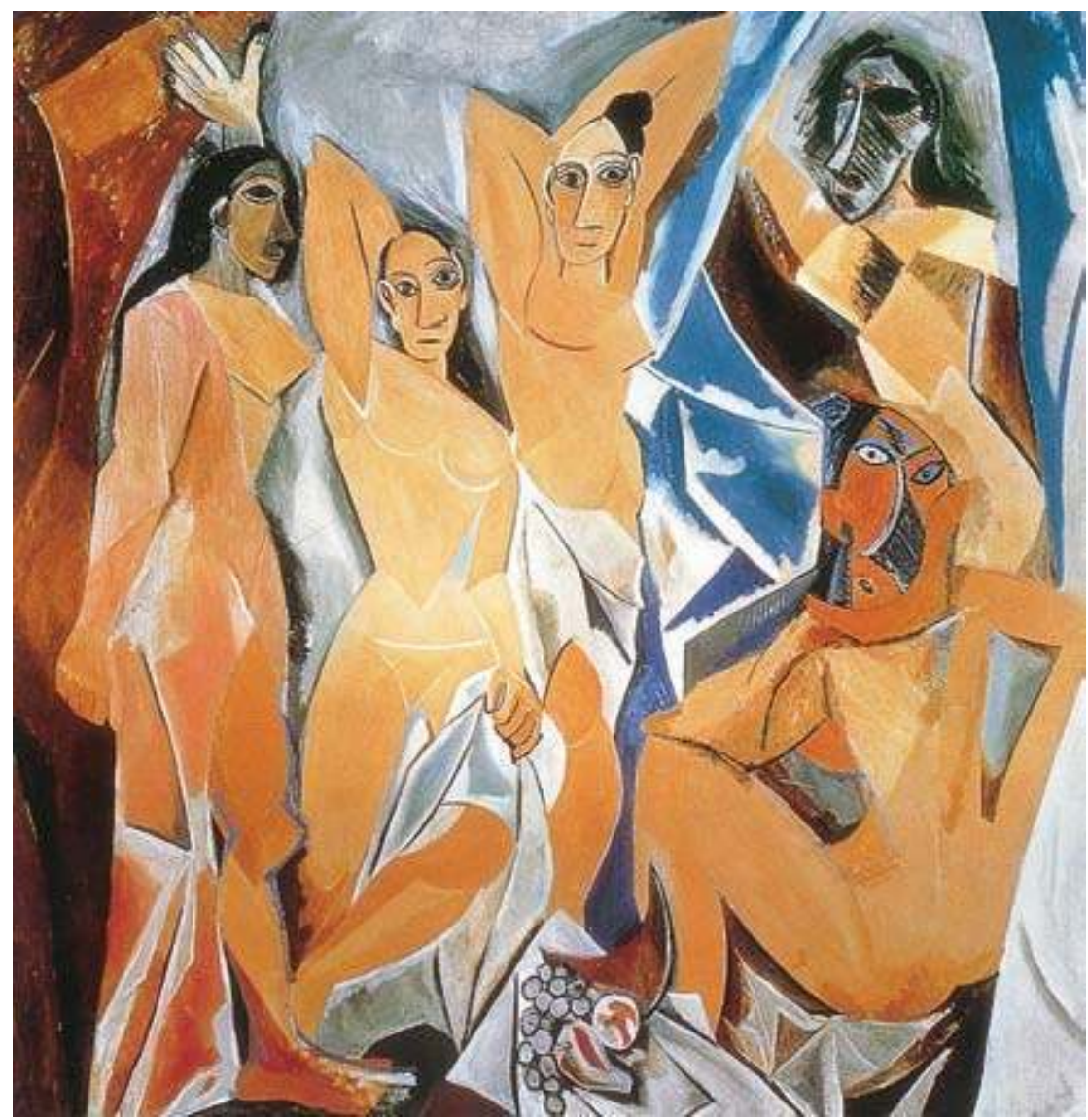

FIGURA 2 - Picasso, Les Démoiselles D'Avignon, 1907

a um espectador ideal: os olhares das mulheres representadas dirigem-se a ele - que ocupa a posição de sujeito - e os seus corpos exibem-se para o prazer do olhar dele. Em resumo: na arte ocidental, dominada pelo desejo masculino - o desejo de possuir a mulher/imagem, o desejo de dominar o objecto e o desejo de fantasiar o desejo -, a mulher tem sido largamente representada de acordo com determinados papéis estereotipados, que códigos estéticos se encarregam de disfarçar: musa, modelo, madona, prostituta, ícone religioso ou foto pornográfica (cf. Robinson, 1995: 140).

Não foi apenas no passado que o público masculino se deleitou com o nu feminino, como podem comprovar os inúmeros exemplos ao longo da história da pintura. Mesmo hoje este tema está presente em vários pintores. Queremos citar dois exemplos de dois pintores contemporâneos, escolhidos 
entre os vários possíveis, em que, embora formalmente de estilos diferentes, é possível reconhecer o male gaze e o olhar colonizador, estruturados segundo as premissas: o homem/espectador e a mulher passiva/espectáculo. Falamos de Lucian Freud e de Balthus.

Aos 85 anos, numa visita ao Victoria and Albert Museum, Lucian Freud ${ }^{14}$ encontrou o tema para a sua pintura seguinte quando viu Ria Kirby, de 26 anos, que aí trabalhava. $\mathrm{O}$ artista convidou-a para posar nua, e menos de 24 horas depois ela estava no atelier dele. A pintura, que veio a receber o título de "Ria, Naked Portrait 2007", foi iniciada em Abril de 2006 e levou um ano e quatro meses a completar. Segundo o Sunday Telegraph, de 22 de Setembro de 2007, as sessões foram realizadas sete noites por semana, num total de 2400 horas. O progresso do trabalho foi acompanhado por um fotógrafo. O Sunday Telegraph citado publicou uma dessas fotografias, que mostra o quadro já pronto, o modelo nu deitado numa cama e o artista de paleta e trapos sujos de tinta na mão, de olhos postos na objectiva. ${ }^{15}$ Perante este belo quadro de Freud, não deveremos perguntar-nos se não se observa aqui um olhar idêntico ao de "Susana e os Velhos"?

As meninas ${ }^{16}$ de Balthus ${ }^{17}$ aparecem como que a oferecer-se distraidamente. Ele é uma espécie de bonecreiro que as expõe ao olhar do predador sexual. Estes nus de meninas na puberdade contêm um erotismo latente, dirigido ao espectador subentendido. A parte genital das meninas está escondida, mas só parcialmente, chamando assim atenção para ela. A pintura Retrato de André Derain, 1936, representando um homem com um roupão às riscas [fig. 3], sugere a possibilidade de actividade sexual. Balthus defendia, no entanto, que essas obras não eram pornográficas, afirmando que levavam ao reconhecimento de factos desconfortáveis da sexualidade infantil. ${ }^{18}$ A sua obra "Lição de Guitarra" causou escândalo devido ao explícito da situação retratada: uma professora segura uma adolescente deitada no seu colo, em atitude altamente provocadora. ${ }^{19}$ Apesar do escândalo que

\footnotetext{
${ }^{14}$ Lucian Freud nasceu em 1922, em Berlim. Neto de Sigmund Freud, imigrou para Inglaterra em 1933 com toda a família, em fuga das perseguições do nazismo aos judeus.

${ }_{15}$ Artigo acessível em http://www.telegraph.co.uk/culture/3668104/Lucian-Freud-marathonman.html.

${ }_{16}$ Teresa sonhando, 1938; A lição de guitarra, 1934; Rapariga com gato, 1937; Retrato de André Derain, 1936, Alice ao espelho, 1933.

${ }^{17}$ De seu nome Balthazar Klossowski de Rola, nasceu em Paris, em 1908, filho de um conde polaco e de Elisabeth Dorothea Spiro, de quem se diz ter sido "musa" do poeta alemão Rainer Maria Rilke. Não tendo feito estudos formais de arte, pintava inspirado em Rilke e sob orientação de alguns artistas, entre os quais Bonnard e Matisse (http://en.wikipedia.org/wiki/Balthus).

${ }_{18}$ Curioso é o facto de não ter utilizado as mesmas sugestões eróticas quando pintou o retrato do pintor Joan Miró e sua filha Dolores, 1937-38.

19 Sobre este quadro consultar também Bernard Géniès \& Judicaël Lavrador (2007).
} 


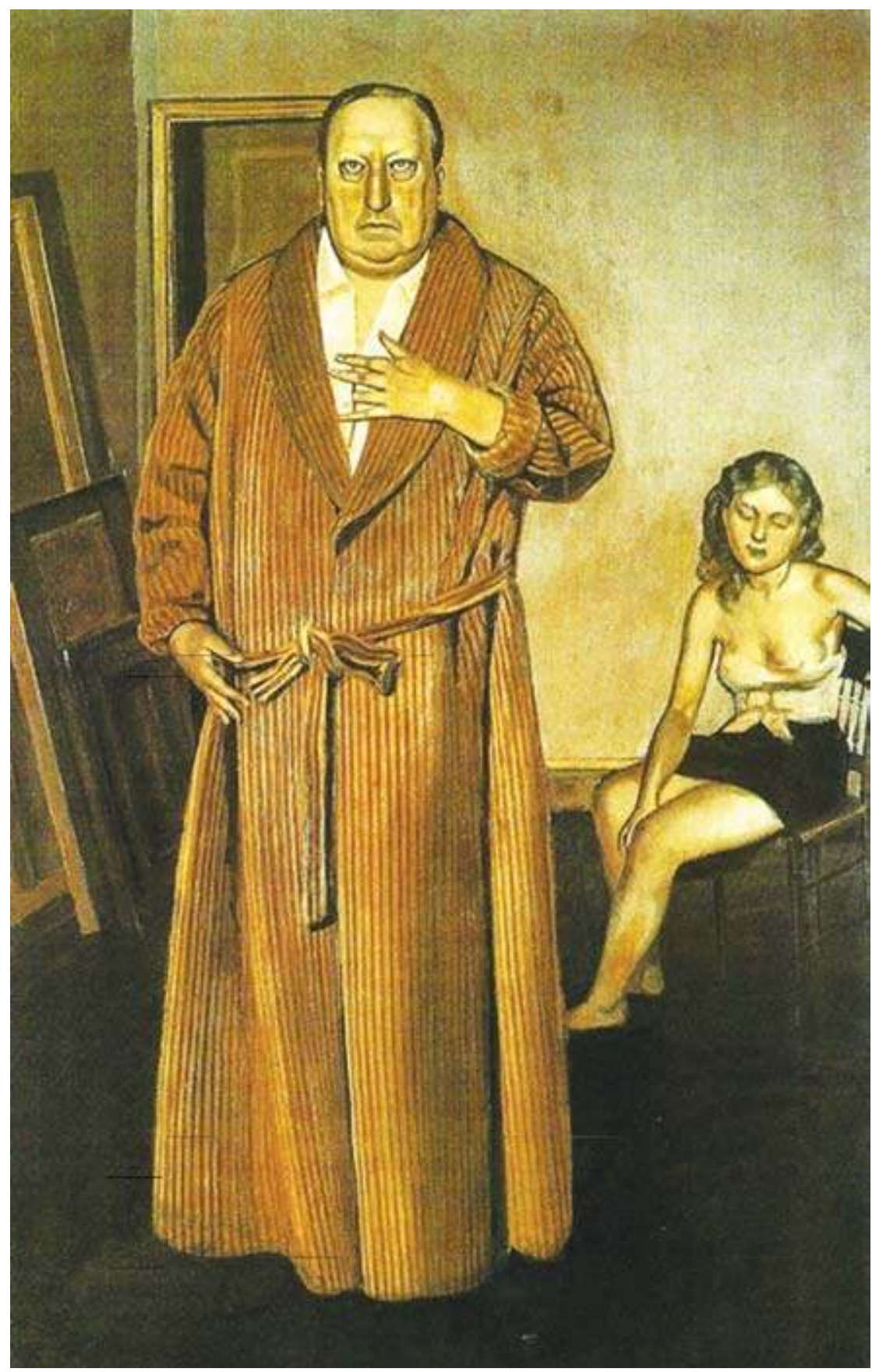

FIGURA 3 - Balthus, Retrato de André Derain, 1936 
provocou, a pintura foi admirada por artistas, escritores e poetas masculinos da intelectualidade da esquerda francesa, como Camus, Saint-Éxupery e Malraux. ${ }^{20}$ Griselda Pollock (2001: 123), no seu ensaio sobre a modernidade e os espaços da feminilidade, chama a atenção para o facto de não ser possível encontrar pinturas feitas por mulheres em que estas definam a sua sexualidade em torno da representação de um nu masculino.

Encontramos artistas masculinos mais recentes em cujo trabalho o nu feminino-surge como outra forma de olhar. Podemos citar, entre outros, Ron Mueck. Nas esculturas de Mueck, ${ }^{21}$ em escalas muito diversas, desde miniaturais a colossais mas nunca do tamanho real, encontramos nus, masculinos e femininos, entre figuras de outro tipo. A fibra de vidro tornou-se o seu mármore e o seu bronze. Este escultor hiper-realista trata o nu feminino não apenas como objecto de desejo, mas dando lugar e visibilidade a figurações do corpo feminino em situações normalmente evitadas, escondidas e silenciadas, tal como a mulher grávida e o parto. ${ }^{22}$ [fig. 4]

\section{Mulheres que pintam corpos (nus) femininos}

Até ao século XX, não aparece nunca uma mulher pintora como pintora de nus, sejam eles masculinos ou femininos. A excepção - tanto quanto é conhecida da história de arte - é a já referida Artemisia Gentileschi, no século XVII, mas cuja autoria de "Susana e os Velhos" não era reconhecida. $\mathrm{Na}$ viragem do século XIX para o século XX a situação muda. Entre as autoras de nus femininos podemos citar, por exemplo, Paula Modershon-Beker (1876-1907) e Suzanne Valadon (1865-1938). Suzanne Valadon ${ }^{23}$ trabalhou bastante o modelo nu feminino. No entanto, os críticos não foram capazes de separar as suas pinturas de nu do seu estatuto de modelo para a criatividade masculina. No modernismo, afirmava-se que a arte não tinha

\footnotetext{
${ }^{20}$ Malraux, na sua condição de ministro da cultura, chega mesmo a convidá-lo para director da Academia Francesa em Roma (http://en.wikipedia.org/wiki/Balthus\#life_and_work).

${ }^{21}$ Ron Mueck nasceu na Austrália, em 1958, filho de pais operários de fabrico de brinquedos. Estabeleceu-se mais tarde em Inglaterra, tendo criado a sua própria empresa. A partir de 1996, passou para o campo das Belas Artes, colaborando com Paula Rego - sua sogra - na produção de figuras do tableau que a artista portuguesa expôs então na Hayward Gallery. Desta colaboração resultou a sua passagem do mundo da publicidade para o mundo da arte. Foi com a escultura "Dead Dad" que se tornou conhecido (www.paintalicious.org/2007/09/14/ron-mueck-hyper-realist-sculptor/).

${ }^{22}$ Estamos a referir-nos às seguintes pinturas de Ron Mueck: Mulher grávida, 1997; Mãe e criança, 2001 (a) e Mãe e criança, 2001 (b).

${ }^{23}$ Suzanne Valadon era filha ilegítima de uma mulher do campo, tendo dado à luz aos 18 anos o seu único filho também "natural" (Maurice Utrillo, que também será pintor). O seu nome próprio era Marie-Clementine e foi Toulouse Lautrec, com quem ela teve uma relação mais longa, que a baptizou de "Suzanne", pois, dizia ele, "ela era a preferida dos velhotes" (Chadwick, 1996).
} 


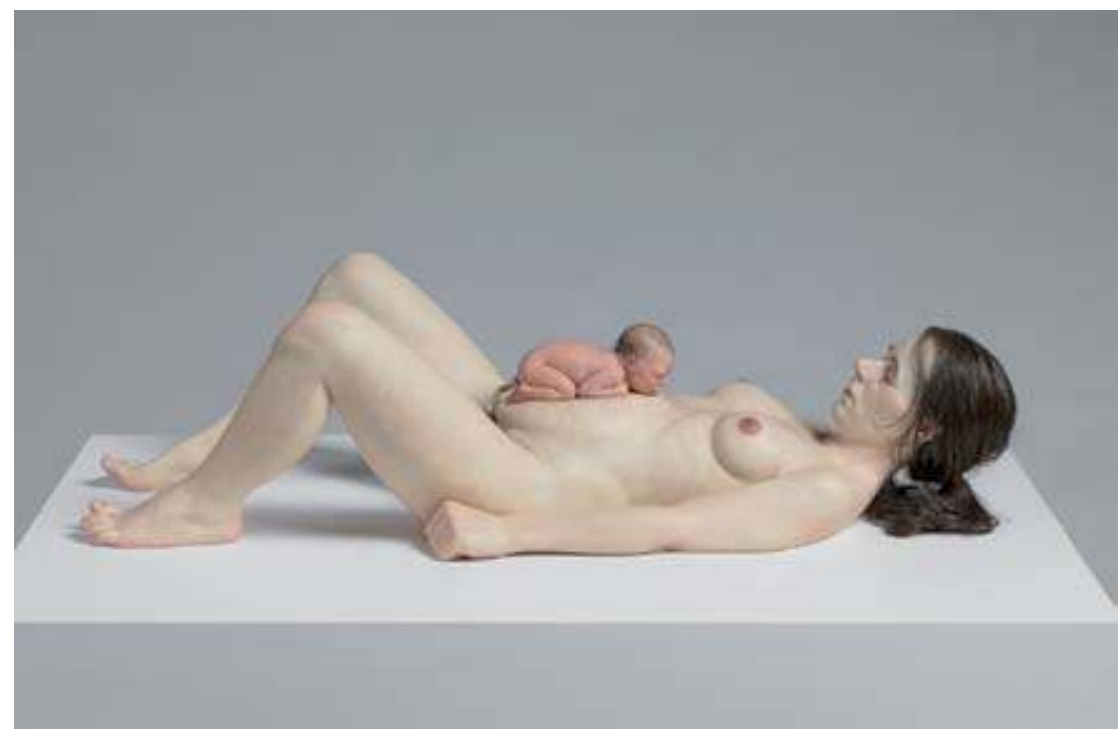

FIGURA 4 - Ron Mueck, Mother and Child, 2001

sexo; no entanto, no caso da pintura de Valadon, dizia-se que "pintava com poder masculino" e "virilidade" (Chadwick, 1996: 282).

$\mathrm{Na}$ sua carreira de modelo, Valadon, que fez parte da vida boémia parisiense no princípio do século Xx, posou para Toulouse-Lautrec, Degas, Renoir e outros artistas, cujas práticas incluíam uma visão "livre" da sexualidade. Os nus de Valadon reflectem simultaneamente a sua experiência como modelo e o seu autoconhecimento do corpo da mulher. Como afirma Chadwick, esta artista domina bem a técnica da representação do corpo nu, porque, "em vez de apresentar o corpo da mulher como superfície de desejo, isolada e controlada pelo olhar masculino, enfatiza os gestos incómodos das figuras, controlando os movimentos da mulher" (1996: 286). Valadon coloca as suas figuras em cenários domésticos específicos, como, por exemplo, nas pinturas "Avó e jovem rapariga a entrar para o banho" e "Nu com colcha às riscas". Estes trabalhos apresentam uma notável diferença dos produzidos pelos seus contemporâneos, como Renoir.

Suzanne Valadon é o primeiro caso da história da pintura de transformação de modelo em criadora. Quando artista já consagrada, pediu a Toulouse-Lautrec que posasse para ela, o que ele recusou, "uma vez que isso supunha uma troca de papéis" (Pérez Gauli, 2000: 81). Para as artistas feministas, o uso do próprio corpo como forma de poder do seu corpo e sobre o seu corpo constitui uma forma de luta contra o uso do corpo feminino como apenas 
objecto de desejo masculino. Trata-se de uma forma de arte cuja manifestação está condicionada pela presença "ao vivo" do corpo sem o qual não pode acontecer. Difere da pintura onde o corpo é uma causa anterior ou formal, porque elege o corpo, não apenas como instrumento dispositivo técnico, mas também como resíduo, como no caso do trabalho Train, de Kiki Smith, onde é visível a dimensão residual na representação que remete para o referencial da menstruação.

A utilização do corpo como ferramenta na arte e, simultaneamente, como manifesto anti-patriarcal não é pacífica entre artistas feministas. A estratégia é recusada, por exemplo, por artistas como Mary Kelly (Documento Post Partum, 1978-9) ou Susan Hillary (Self-portrait, 1983), que trabalham numa linha mais conceptual e optam por uma construção da identidade feminina recorrendo a uma linguagem gráfica e afastando-se, portanto, da linguagem plástica e da figuração do corpo. Artistas e historiadoras da arte feministas, como Griselda Pollock e Mary Kelly, nas décadas de 1970 e 1980, articularam uma teoria da prática plástica feminista que repudiava a representação ou a colocação em cena do corpo feminino, com o argumento de que as estratégias de visualização do corpo reproduziam inevitavelmente as estruturas do fetichismo (Jones, 2007: 57).

\section{Notas conclusivas}

Podemos concluir que, no mundo das artes, as mulheres foram sendo ou excluídas e/ou relegadas para práticas menos valorizadas por condicionalismos como a exclusão da pintura de modelo nu, exercida só por homens, ficando circunscritas à prática dos temas considerados de menos prestígio.

Aqui se reflectiu sobre algumas formas de violência no olhar, muitas vezes não identificadas mas nem por isso menos violentas. Constata-se, pois, que o uso e abuso dos papéis da mulher no mundo da pintura têm andado a par de uma certa prática de machismo que ainda persiste nos meios artísticos, devendo-se sublinhar que a pertença a uma família cultural e/ou artística não pode absolver qualquer forma de discriminação sexual. Como afirma Deborah Haynes e nós subscrevemos, "como parte de uma nova consciência do pluralismo cultural, as mulheres artistas e artistas de cor contribuíram com críticas significativas ao modernismo" (1997: 151). Estes novos tempos de pós-modernidade apresentam novas questões acerca da "exploração dos enviesamentos de sexo, raça e classe, dos cânones e tradições modernistas, de imagens de sexualidade e subjectividade e de políticas de criação e de representação" (idem: idem). Este questionamento foi feito, em larga medida, e continua a ser feito, por artistas e escritoras dos grupos sociais considerados minorias. 


\section{Referências bibliográficas}

Adams, Laurie (1996), The Methodologies of Art: An Introduction. Oxford: Westview Press.

Addiss, Stephen; Erickson, Mary (1993), Art History and Education (Disciplines in Art Education). Chicago: University of Illinois.

Barreno, Isabel (1985), O falso neutro. Lisboa: Edições Rolim.

Berger, John (1972), Modos de ver. Lisboa: Edições 70.

Chadwick, Whitney (1996), Women, Art, and Society. London: Thames and Hudson.

Collins, Georgia; Renee Sandell (1987), “Women's Achievements in Art: An Issues Approach for the Classroom", Art Education, May, 40(3), 12-21.

Cruz, Angélica; Magalhães, M. José (2009), "Susana e os Velhos: tema recorrente na arte e na vida”, in Anabela Correia e Eduarda Coquet (coords.), Diálogos com arte. Braga: CESC, Universidade do Minho, 11-22.

Cruz, Angélica (2002), Clay Figurines of Galegos; An Anthropology of Artistic Production made by Women in Northern Portugal. Tese de Doutoramento. Londres: Universidade de Surrey Roehampton.

Garrard, Mary (1982), “Artemisia and Susanna”, in Norma Broude e Mary D. Garrard (orgs.), in Feminism and Art History: Questioning the Litany. New York: Harper \& Row Publishers.

Geniès, Bernard; Judicaël Lavrador (2007), "La vie sexuelle des artistes aux rayons X", Beaux Arts magazine, ART E SEXE. Paris: Publication de TTM Group, 80-82.

Hammond, Harmony (2006), "Against Cultural Amnesia” [11994], in Hilary Robinson (coord.) (2006), Feminism - Art- Theory: An Anthology 1968-2000. Oxford: Blackwell Publishing, 555-561.

Harris, Jonathan (2001), The New Art History. A Critical Introduction. London: Sage.

Haynes, Deborah J. (1997), The Vocation Of The Artist. Cambridge: The University Press.

Jones, Amelia (2007), “1970/2007: O legado da arte feminista”, in A Batalla dos Xéneros, Catálogo da Exposição de 13 de Setembro a 9 de Dezembro 2007 no Centro Galego de Arte Contemporánea. Junta de Galicia, 51-65.

Lippard, Lucy (1995), The Pink Glass Swan: Selected Feminist Essays on Art. New York: The New Press.

Lippard, Lucy (2006), "Hot Potatoes: Art and Politics in 1980" [11981], in Hilary Robinson (2006), (coord.), Feminism - Art - Theory: An Anthology 1968-2000. Oxford: Blackwell Publishing, 107-118.

Mulvey, Laura (1975), "Visual Pleasures and Narrative Cinema", in Screen, Autumn, 16(3), 6-18.

Nochlin, Linda (1989), "Why Have There Been No Great Women Artists?”, in Nochlin, Women, Art, and Power and Other Essays. London: Thames and Hudson, 145-178 [originalmente publicado em Art News, 69, Janeiro, 1971]. 
Parker, Roziska; Griselda Pollock, (1981), Old Mistresses: Women, Art and Ideology. Londres: Pandora Press.

Pérez Gauli, Juan Carlos (2000), "El pintor y la modelo, historia de una desigualdad”, in Marián L. F. Cao (coord.) (2000), Creación Artistica y Mujeres: Recuperar la Memoria. Madrid: Narcea Ediciones.

Perry, Gill (1999), "Women Artists, 'Masculine' Art and the Royal Academy of Art", in Gill Perry (1999) (coord), Gender and Art. London: Yale University Press in association with The Open University, 90-107.

Pollock, Griselda (2001), "Modernity and the Spaces of Femininity”, in Francis Frascino e Jonathan Harris (orgs.), Art in Modern Culture: An Anthology of Critical Texts. London: Phaidon.

Pollock, Griselda (2007), "O Feminismo: un Fenómeno Mundial que Chegou ata a Universidade. Reflexións sobre a Influencia do Feminismo no Pensamento e a Arte desde 1970", in A Batalla dos Xéneros, Catálogo da Exposição de 13 de Setembro a 9 de Dezembro 2007 no Centro Galego de Arte Contemporánea. Junta de Galicia, pp 99-104.

Robinson, Hilary (1995), "Border Crossing: Womanliness, Body, Representation”, in Katy Deepwell (org.), New Feminist Art Criticism: Critical Strategies. Manchester and New York: Manchester University Press, 139-146.

Rose, Gillian (2005), Visual Methodologies. London: SAGE Publications Ltd.

Santos, Maria Irene Ramalho (1980), “A escrita na vida da gente: sobre autobiografias operárias”, Revista Crítica de Ciências Sociais, 4-5, 117-127.

Sturken, Marita; Lisa Cartwright (2001), Pratices of Looking. Oxford: Oxford University Press.

Vasari, Giorgio (1998), The Lives of the Artists. New York: Oxford University Press. Wagner, Anne Middleton (1996), Three Artists (Three Women): Modernism and the Art of Hesse, Krasner and O'Keeffe. Berkeley: University of California Press.

\section{Créditos das imagens}

Fig. 1: Artemisia Gentileschi, Susana e os Velhos, 1610

Fig. 2: Picasso, Les Démoiselles D’Avignon, 1907

(C) 2010, Succession Pablo Picasso, SPA

Fig. 3: Balthus, Retrato de André Derain, 1936

(C) Balthus, ADAGP, 2010

Fig. 4: Ron Mueck, Mother and Child, 2001

(C) Direktion Der Bayerischen Staatsgemäldesammlungen, Munique 